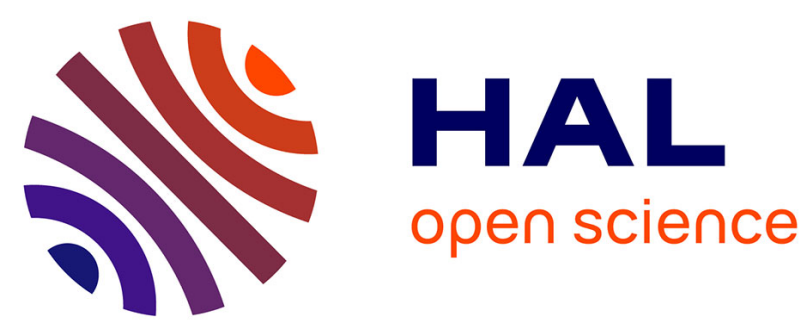

\title{
INSULIN RESISTANCE AND DIABETIC MACULAR EDEMA IN TYPE 2 DIABETES MELLITUS
}

\author{
Miguel Angel Zapata, José Badal, Alex Fonollosa, Anna Boixadera, José
}

García-Arumí

\section{> To cite this version:}

Miguel Angel Zapata, José Badal, Alex Fonollosa, Anna Boixadera, José García-Arumí. INSULIN RESISTANCE AND DIABETIC MACULAR EDEMA IN TYPE 2 DIABETES MELLITUS. British Journal of Ophthalmology, 2010, 94 (9), pp.1230. 10.1136/bjo.2009.171702 . hal-00557345

\section{HAL Id: hal-00557345 https://hal.science/hal-00557345}

Submitted on 19 Jan 2011

HAL is a multi-disciplinary open access archive for the deposit and dissemination of scientific research documents, whether they are published or not. The documents may come from teaching and research institutions in France or abroad, or from public or private research centers.
L'archive ouverte pluridisciplinaire HAL, est destinée au dépôt et à la diffusion de documents scientifiques de niveau recherche, publiés ou non, émanant des établissements d'enseignement et de recherche français ou étrangers, des laboratoires publics ou privés. 
TITLE

INSULIN RESISTANCE AND DIABETIC MACULAR EDEMA IN TYPE 2 DIABETES MELLITUS 


\section{ABSTRACT}

Objective: To evaluate the association between insulin resistance and diabetic macular edema in type 2 diabetes.

Methods: Cross-sectional study. Type 2 diabetes patients who agreed to undergo blood sample extraction were enrolled. Patients who had received treatment for macular edema within the past 3 months and those with other retinal diseases were excluded. The following data were recorded: age, sex, time of diabetes evolution, $\mathrm{HbA} 1 \mathrm{C}$, ophthalmologic and systemic treatment, and lens status. Optical coherence tomography (OCT) was performed to determine the morphologic patterns of macular edema. Insulin resistance was established on a McAuley index of $<6.3$ and fasting insulin levels of $>16 \mathrm{mU} / \mathrm{L}$.

Results: 177 eyes from 90 patients were included; $27.1 \%$ of eyes were from insulin-resistant patients. There were no differences in age, time of evolution, sex, HbA1C level, or lens status between insulin-resistant and nonresistant patients. Insulin-resistant patients were more likely to have exogenous insulin therapy $(P<0.05 ; \mathrm{OR}=3.8)$. An association was found between diabetic cystoid macular edema and resistance (Fisher exact test $P=0.007 ; \mathrm{OR}=2.53,95 \% \mathrm{CI}: 1.52-4.2$ ). There were no associations between insulin resistance and the other morphologic patterns of edema. Patients undergoing insulin therapy were found to have an association with a diffuse retinal thickening pattern on OCT $(P=0.036 ; \mathrm{OR}=1.4)$. However, no association was found between insulin therapy and the presence of cystoid macular edema.

Conclusions: The findings of this study indicate a relationship between insulin resistance and cystoid macular edema, which is unrelated to the use of insulin. Insulin treatment was associated with diffuse macular edema.

None of the authors have any financial interests to disclose. 


\section{INTRODUCTION}

Type 2 diabetes mellitus is the most common metabolic disease worldwide. Whereas low plasma insulin levels are seen in type 1 diabetes mellitus, insulin resistance is a characteristic feature in type 2 patients. Macular edema is a major complication of diabetes and is the leading cause of blindness in patients aged 25 to 74 in developed countries.

The origin of diabetic macular edema resides in a series of local and systemic injuries to the retina, including vascular dysfunction, neural degeneration, and retinal inflammation. It remains unclear whether diabetic retinopathy is initiated by vascular dysfunction leading to neural degeneration and subsequent inflammation, or by dysregulation of the neural retina metabolism with subsequent inflammation and vascular damage (1).

The relationship between diabetes mellitus and inflammation was first recognized more than 60 years ago $(2,3)$, and recently an association between insulin resistance and systemic inflammation was reported $(4,5)$. Abnormalities in glucose and lipid metabolism, obesity, and high blood pressure occur together commonly enough in the same individuals as to suggest that they are somehow interrelated. This cluster of metabolic abnormalities is attributable to insulin resistance; that is, a reduced sensitivity to the action of insulin in tissues. In the early stages of this condition there is a compensatory state of hyperinsulinemia, and later on, hyperglycemia. Insulin resistance is an inherently proinflammatory state that begins before the onset of overt hyperglycemia and is related in part to excess nutrients in adipose tissue, skeletal muscle, and the liver. Inflammation induces a catabolic state that counteracts normal anabolic processes, probably as an adaptive mechanism to prevent excessive cellular 
nutrient uptake. Systemic inflammation increases with the onset of clinical diabetes and contributes to the development of complications, including nephropathy and retinopathy. In addition, high insulin levels have a vasoreactive effect that results in increased permeability of the retinal vessels $(6,7)$.

Insulin resistance has been investigated and correlated with clinical risk factors, mainly in nondiabetic patients. Direct methods (the reference standard) can be used to measure insulin resistance, but they are complex to perform and expensive. Indirect measures of insulin resistance, such as fasting insulinemia (8) and mathematical models, have shown a good correlation with the reference standard in non-diabetic patients (9).

\section{OBJECTIVE}

This study evaluates the association between an indirect measure of insulin resistance and diabetic macular edema in type 2 diabetes mellitus patients, specifically the cystic type, and assesses the effect of exogenous insulin treatment on macular edema.

\section{METHODS}

This is a cross-sectional study performed in a clinic- and hospital-based population, enrolled over a 3-week period in our hospital's general ophthalmology department and dedicated retinal outpatient clinic. The study included all type 2 diabetes patients who agreed to undergo blood sample extraction. Patients who had received treatment for macular edema within the past 3 months and those with other retinal diseases were excluded.

The following data were recorded in all cases: age, sex, time of diabetes evolution, HbA1C levels, ophthalmologic and systemic treatment, and lens status. The Early Treatment Diabetic Retinopathy Study (ETDRS) criteria 
were used to determine whether clinically significant macular edema (CSME) was present or not. In patients with CSME, optical coherence tomography (OCT) (Stratus OCT Humphrey Zeiss Inc, San Leandro, California, USA, software version 4.0) was performed to determine the morphologic patterns of macular edema according to the classification of Kim et al (10). OCT scans were graded by one trained reader according to the predominating morphologic patterns present: type I, diffuse retinal thickening; type II, cystoid macular edema; type III, serous retinal detachment without posterior hyaloidal traction; type IV, posterior hyaloidal traction without traction retinal detachment; and type $\mathrm{V}$, traction retinal detachment.

Blood samples were collected from all patients. Insulin resistance was established on a McAuley index of $<6.3$ and fasting insulin levels of $>16$ $\mathrm{mU} / \mathrm{L}(8,11)$.

Determination of sample size was based on the normal asymptotic confidence interval for the estimated occurrence of an event in an infinite population, considering the percentage of insulin resistance in the general population (9) to be $32 \%$ (95\% confidence interval) to achieve an accuracy of $\pm 10.0 \%$. The calculation was performed with ENE 2.0 software (Biometry Department of GlaxoSmithKline and Statistics Service of the Autonomnous University of Barcelona). At least 84 patients were required to fulfill these conditions, and 90 were ultimately included in the study. Results were analyzed with SPSS, version 15.0. The Student $t$ test for independent samples was used to compare patients with and without insulin resistance. Associations were studied in $2 \times 2$ tables with the chi-square and Fisher's exact test. Odds ratios were calculated at a $95 \%$ confidence interval (CI).

All patients signed an informed consent form to participate, and the study was approved by the local ethics committee. 


\section{RESULTS}

A total of 177 eyes from 90 patients with type 2 diabetes were included in the study; $27.1 \%$ of eyes were from insulin-resistant patients. There were no differences in age, $\mathrm{HbA1c}$, time of evolution of diabetes, sex, or lens status between the insulin-resistant and nonresistant patients. However, these groups showed some differences related to the treatment received: insulin-resistant patients were more likely to have exogenous insulin therapy $(P<0.05$; $\mathrm{OR}=3.8)$.

The morphologic patterns of diabetic macular edema differed according to whether or not the patients were insulin resistant $(P=0.031)$ (Tables 1 and 2, Figure 1). When each morphological pattern was compared with insulin resistance, an association was found between diabetic cystoid macular edema (type II) and resistance (Fisher exact test $P=0.007$; OR $=2.53,95 \%$ CI: 1.52-4.2) (Tables 3 and 4). There were no associations between insulin resistance and the other morphologic patterns of diabetic macular edema. In addition, patients undergoing insulin therapy were found to have a direct association with a diffuse retinal thickening pattern on OCT (type I) $(P=0.036 ; \mathrm{OR}=1.4)$. However, no association was found between insulin therapy and the presence of cystoid macular edema $(P=0.78)$.

\section{DISCUSSION}

Direct methods, the reference standard for determining insulin resistance, are difficult to perform and expensive; thus, they are not recommended for epidemiologic or clinical studies (9). Insulin resistance was established as fasting insulin levels $>16 \mathrm{mU} / \mathrm{L}$ in the Paris Study (8), which, to our knowledge, is one of the most important prospective studies on this subject. 
The McAuley index has been described as the most sensitive and specific indirect method to evaluate resistance to insulin (9). McAuley et al. define insulin resistance as a score of $<6.3$ (11). Although these methods have been validated in non-diabetic patients, we have used them in our diabetic population as a simple way to evaluate insulin resistance for the purpose of our study. To provide a stricter definition of resistance, we used both methods-fasting insulin levels and the McAuley index-in the patients studied.

The fact that some of our patients were treated with exogenous insulin may have led to an increase in fasting insulin levels, but we consider this an indirect parameter of resistance. Treated patients need more insulin units per kilo because the hormone is less efficiently, and this results in higher fasting insulin levels. The concept of insulin resistance includes exogenous and endogenous insulin. For this reason, we did not differentiate between exogenous/endogenous insulin levels at the time of blood analysis.

Our results showed an association between insulin resistance and exogenous treatment with insulin. It is reasonable that resistant patients would need higher doses of insulin for metabolic control, and this would require exogenous intake of the hormone.

Each patient's eyes were analyzed separately because the presence and type of macular edema was different between eyes in some cases.

The main finding of our study is the differing morphological pattern of macular edema related to insulin resistance and, of course, the association between cystoid macular edema and insulin resistance. As was mentioned above, insulin resistance is a proinflammatory state, and the pattern of edema found in these patients is very similar to the pattern seen in inflammatory diseases such as Irvine-Gass syndrome and uveitis (12). In fact, the pathogenesis of cystoid edema includes both vasoreactivity and chronic inflammation (13), which we believe may be a result of the 
patient's insulin-resistant status. In other diseases such as vein occlusion, which are primarily considered vascular events, it has been reported that an inflammatory factor and clinical cystoid macular edema are often present (14).

To define whether the association we found was only related to resistance or was also due to insulin treatment, we investigated the relationship between insulin and macular edema. The fact that a patient is receiving insulin therapy seems to have no relationship with cystoid macular edema. However, there was an association with a pattern of diffuse retinal thickening, perhaps a result of the vasoreactive effect of insulin $(6,7)$.

The potential limitations of our study arise from the design and inclusion criteria. This is a cross-sectional clinic- and hospital-based population study with a broad range of inclusion criteria, a simple "photograph" of our patients that involves no treatment interventions. Therefore, there is the possibility of some bias, such as ongoing treatment for macular edema in the 3 months before inclusion, or OCT reading by only one observer. Nonetheless, we believe that our cohort provides a close representation of daily practice, with patients consulting at our specialized retinal outpatient clinic and our general ophthalmology department, which implies that patients with and without diagnosed diabetic retinopathy were included. This is also the reason why there are many more patients in the group without edema than in the group of DME.

The sample size was difficult to determine. We knew the prevalence of cystoid macular edema in the diabetic population, but we did not know the prevalence of insulin-resistant patients with macular edema or with diabetes. Our sample size reflects the percentage of resistance in the population, but the number of participants was not determined according to the purpose of the study because there was not enough data in the literature to provide a basis for the calculation. 
Despite these potential limitations, our results indicate that insulin resistance plays a central role in the pathogenesis of macular edema, particularly in the cystoid pattern. Future longitudinal studies, with more accurate inclusion criteria and other methods to evaluate resistance are needed to confirm our findings. It could be of great interest to investigate the association between insulin resistance and local factors of inflammation.

In summary, the findings of this study indicate a relationship between insulin resistance and cystoid macular edema that is not related to the use of insulin. Insulin treatment was associated with diffuse macular edema. Prospective, longitudinal studies are needed to evaluate the role of insulin and insulin resistance in diabetic macular edema.

\section{REFERENCES}

1. Gardner TW, Antonetti DA. Novel potential mechanisms for diabetic macular edema: leveraging new investigational approaches. Current Diab Reports 2008;8:263-269.

2. Menkin V. Diabetes and Inflammation. Science 1941; (93)2419:456458.

3. Wellen Ke, Hotamisligil GS: Inflammation, stress and Diabetes. J Clin Invest 2005;115:1111-1119.

4. Shoelson SE, Lee J, Goldfine AB. Inflammation and insulin resistance. J Clin Invest. 2006;116(7):1793-801

5. de Luca C, Olefsky JM. Inflammation and insulin resistance. FEBS Lett. 2008; 582(1):97-105.

6. Poulaki Vassiliki, Qin Wenyin et al. Acute intensive insulin therapy exacerbates diabetic blood-retinal barrier breakdown via hypoxiainducible factor-1 alpha and VEGF.2002. J.Clin.Invest. 109:805-815 
7. Zapata MA, Losada E, Fonollosa A, Farrando J. Martinez-Castillo V, Boixadera A, Hernández C, Simó R, García-Arumí J Blurred Vision and increased macular volume in the introduction of insulin therapy: a prospective study. ARVO 2007 Fort Lauderdale, Florida. USA. Poster Presentation.

8. Fontbonne A, Eschwe`ge E, Cambien F, Richard JL, Ducimetiere P, Thibult N, Warnet JM, Claude JR, Rosselin GE: Hypertriglyceridemia as a risk factor of coronary heart disease mortality in subjects with impaired glucose tolerance or diabetes: results from the 11 year follow-up of the Paris Prospective Study. Diabetologia 32:300-304, 1989

9. Ascaso JF, Pardo S, Real JT, Lorente RI, Priego A, Carmena R. Diagnosisn Insulin resistance by simple quantitative methods in subjects with normal glucose metabolism. Diabetes Care 26:33203325,2003

10.Kim BY, Smith SD, Kaiser PK. Optical Coherence Tomographic Patterns of Diabetic Macular Edema Am J Ophthalmol 2006; $142: 405-412$.

11.Kirsten A. Mc Auley, Sheila M. Williams, Jim I. Mann, Robert J. Walker, Nick J. Lewis-Barned, Lara A. Temple, Ashley W. Duncan. Diagnosing Insulin Resistance in the general population. Diabetes Care 2001; 24(3): 460-64.

12.Martin NF, Green WR, Martin LW. Retinal phlebitis in the IrvineGass syndrome. Am J Ophthalmol 1977; 83:377-386.

13.Ryan SJ. Retina. Volume 3. Surgical Retina. 114 Vitreoretinal Interface. Fourth edition 2006. Elsevier Inc.

14. Noma H, Funatsu H, Mimura T, Harino S, Hori S. Vitreous levels of interleukin-6 and vascular endothelial growth factor in macular 
edema with central retinal vein occlusion. Ophthalmology. 2009; 116(1):87-93. 


\section{Figure Legend}

Figure 1

Association between macular edema pattern and insulin resistance 


\section{STATEMENT}

"I Josep Badal, the Corresponding Author of this article (INSULIN RESISTANCE AND DIABETIC MACULAR EDEMA IN TYPE 2 DIABETES MELLITUS) has the right to grant on behalf of all authors and does grant on behalf of all authors, a licence to the BMJ Publishing Group Ltd and its licensees, to permit this Contribution (if accepted) to be published in British Journal of Ophthalmology (BJO) and any other BMJ Group products and to exploit all subsidiary rights, as set out in our licence set out at:

(http://bjo.bmj.com//ifora/licence.pdf).

Please tick one or more boxes as appropriate:

I Im the sole author of the Contribution.

$\mathrm{X} I$ am one author signing on behalf of all co-owners of the Contribution.

_ The Contribution has been made in the course of my employment and I am signing as authorised by my employer.

_ I am a US Federal Government employee acting in the course of my employment.

_ I am not a US Federal Government employee, but some or all of my co-authors are.

_ I am an employee of the UK Government acting in the course of my employment

- I am not an employee of the UK Government acting in the course of my employment but some/all of my co-authors are.

Competing interest: none declared. 